\title{
Impact Toughness of Gas Metal Arc Welded HY-80 Steel Plate at Sub-zero Temperatures
}

\author{
Herry Oktadinata ${ }^{1}$ and Winarto Winarto ${ }^{1, *}$ \\ ${ }^{1}$ Department of Metallurgy and Materials Engineering, Universitas Indonesia, Depok 16424, Indonesia
}

\begin{abstract}
Various welding methods are widely applied in large fabrication of high strength steel. However, commonly the problem occurs where a coarse grain is formed near fusion zone causing reduce the impact toughness due to the weld joint become brittle. Ductility and toughness in a coarse grain heat affected zone (CGHAZ) is low due to the formation of coarsening grain size. The objective of this research is to investigate the microstructure evolution, impact toughness and fracture appearance at sub-zero temperatures of the high strength steel arc welded. The steel that used in this experiment is a HY-80 steel welded by gas metal arc welding (GMAW) with a mixture of argon and carbon dioxide $\left(90 \% \mathrm{Ar}\right.$ and $\left.10 \% \mathrm{CO}_{2}\right)$ and ER100S solid wire. Microstructure observation and Charpy V-notch (CVN) tests were performed on the weld joint which consist of base metal (BM), heat affected zone (HAZ), and weld metal (WM). The CVN tests on the HY-80 steel plate at various temperatures $\left(20,-20,-60\right.$ and $\left.-80{ }^{\circ} \mathrm{C}\right)$ show impact toughness decrease when the test temperature decrease. The CVN tests on the HY-80 weld joint at a temperature of $80{ }^{\circ} \mathrm{C}$ show the lowest impact toughness was measured at WM $(61 \mathrm{~J})$ and followed fusion line-FL (101 J) with brittle fracture appearance.
\end{abstract}

\section{Introduction}

HY-80 is a high strength steel with minimum yield strength of $80 \mathrm{ksi}$ and it was developed in the 1960s for submarine and naval ship construction. This steel is produced in quenched and tempered condition where the microstructure shows tempered bainite martensite [1-3]. HY-80 steel shows a superior combination of strength, ductility, impact toughness, and weldability [1,3-5].

Fusion welding is most commonly applied in fabrication of high strength steel for ship buildings [6-8]. When steel is heated during welding operation, homogeneity of microstructures suddenly changes and influence the mechanical properties. Welding heat input influence microstructure evolution in HAZ, however it depends on the distance from the heat source. Due to microstructure evolution, the mechanical properties (i.e. strength, ductility and toughness) of weld joint change drastically. The microstructure of high strength steel shows tempered martensite, bainite, ferrite and martensite-austenite (M-A) constituents, and there are the segregation of inclusion and precipitation including nitride, carbide, and composite [9]. The problem found in the HAZ near fusion zone due to coarsening grain size formed and degrade the properties of the weld joint $[5,9,10]$. The CGHAZ affect to deteriorate impact toughness due to presence of coarsening grain size and
M-A constituents [5,10,11]. The properties of HAZ are influenced by microstructure which is determined by phase transformation during welding [12]. S. Kumar et al. [13] investigated relation between cooling rate and impact toughness in HAZ of HY-85 steel. The impact toughness in HAZ drastically drop to $26.5 \mathrm{~J}$ compare to $226.5 \mathrm{~J}$ in $\mathrm{BM}$ when very low cooling rate $(5 \mathrm{~K} / \mathrm{s})$ applied. Impact toughness increase from cooling rate 5 $\mathrm{K} / \mathrm{s}$ up to $80 \mathrm{~K} / \mathrm{s}$ when bainite formed, and then decrease when the cooling rate exceed $80 \mathrm{~K} / \mathrm{s}$ due to fully martensite formed [13]. Controlling the cooling time at low temperature prevented cold cracking at high strength steel weldment [14].

Impact toughness of high strength steel welded joints is also influenced by welding method. The elements reduction due to the oxidation effects of the shielding gas can reduce the impact toughness of WM [3]. Pamnani et al. [7] reported the submerged arc welding (SAW) which resulting number of inclusions greater than shielded metal arc welding (SMAW) and flux-cored arc welding (FCAW) show the lowest impact toughness at WM. Impact toughness of WM at sub-zero temperatures is affected by chemical composition of WM, grain size, acicular ferrite microstructure and inclusions $[7,10,15]$. Chemical composition of filler metal (welding wire) influences composition of WM. Higher concentration of nickel in WM stabilizes austenite grain, hence improves impact toughness at sub-

Corresponding author: winarto@metal.ui.ac.id 
zero temperatures. Increasing welding heat input resulting larger austenite grain size and decreasing impact toughness. Size and volume fraction of nonmetallic inclusions influence formation of acicular ferrite which contribute to improve impact toughness.

Microstructural constituents in WM are influenced by the oxygen and carbon dioxide amount in the shielding gas used [15,16]. S. Mukhopadhyay et al. [16] reported the formation of acicular ferrite has a benefit on impact toughness in the absence of other brittle zones. A small amount of oxygen addition up to $4 \%$ in the shielding gas mixture $\left(\mathrm{Ar}+\mathrm{CO}_{2}+\mathrm{O}_{2}\right)$ of the GMAW method can improve ductility and impact toughness of WM due to increasing proportions of acicular ferrite. Microstructural aspects influence fracture micromechanism of deteriorated HAZ toughness [17]. S. Kumar et al. [5] suggested that the impact toughness values of HY-85 welded joint are relatively constant between room temperature to $-50{ }^{\circ} \mathrm{C}$ for $\mathrm{BM}$ as well as CGHAZ, further result show the impact toughness drastically decreases with decrease in test temperature. R. Pamnani et al. [7] found the increase of acicular ferrite and refined microstructure in WM of high strength low alloy (HSLA) steel result higher sub-zero impact toughness, and the sub-zero impact toughness of the WM was found to be directly proportional to Ni present in the WM.

In this research, $12 \mathrm{~mm}$ thickness of HY-80 steel was welded by using GMAW method. ER100S solid wire and a mixture of argon and carbon dioxide $\left(90 \% \mathrm{Ar}+10 \% \mathrm{CO}_{2}\right)$ were selected for welding consumables. Joint design of butt weld with $60^{\circ} \mathrm{V}$ groove and $50{ }^{\circ} \mathrm{C}$ preheating were applied. This paper describes microstructure evolution and impact toughness of HY-80 steel weld joint. The observations are consist of microstructure analysis in weldment, impact toughness HY-80 at various temperatures $(20,-20,-60$ and $-80{ }^{\circ} \mathrm{C}$ ), and also impact toughness and fracture appearance of $\mathrm{HY}-80$ weld joint at $-80^{\circ} \mathrm{C}$.

\section{Experimental procedure}

\subsection{Materials and welding experiment}

The HY-80 base plate with thickness of $12 \mathrm{~mm}$ was used in this experiment. The chemical composition of this steel was tested by optical emission spectroscopy and the result is provided in Table 1 . The mechanical properties reference according to MIL-S-16216K(SH) are as follows: yield strength $550 \mathrm{~N} / \mathrm{mm}^{2}$, elongation $19 \%$, impact absorbed energy is $81 \mathrm{~J}\left(\right.$ at $-18{ }^{\circ} \mathrm{C}$ ) and $47 \mathrm{~J}$ (at $-84{ }^{\circ} \mathrm{C}$ ).

Two HY-80 steel plates of dimension $300 \times 100 \times 12$ $\mathrm{mm}^{3}$ were used in this experiment. These plates were butt welded with horizontal position as shown in Fig. 1. Single v-groove with $60^{\circ}$ angle joint design was prepared as presented in Fig. 2. Prior to welding, the steel plate was preheated at a temperature of $50{ }^{\circ} \mathrm{C}$ (minimum). The welding method used in this experiment was GMAW with the horizontal position (2G). A mixture of argon and carbon dioxide $(90 \% \mathrm{Ar}$ and $\left.10 \% \mathrm{CO}_{2}\right)$ as shielding gas and $1.2 \mathrm{~mm}$ diameter of ER100S solid wire were used during this welding experiment. The chemical analysis of the solid wire is presented in Table 2 (from the manufacturer). The selected welding parameters in this experiment were determined from experiences and the literatures (Table 3).

Table 1. Chemical analysis (wt.\%) of the tested HY-80 steel

\begin{tabular}{cccccccc}
\hline $\mathrm{C}$ & $\mathrm{Mn}$ & $\mathrm{P}$ & $\mathrm{S}$ & $\mathrm{Si}$ & $\mathrm{Ni}$ & $\mathrm{Cr}$ & $\mathrm{Mo}$ \\
\hline 0.14 & 0.29 & 0.004 & 0.002 & 0.22 & 3.03 & 1.49 & 0.437 \\
\hline
\end{tabular}

Table 2. Chemical composition (wt.\%) of ER100S welding wire (from the manufacturer)

\begin{tabular}{cccccc}
\hline $\mathrm{C}$ & $\mathrm{Si}$ & $\mathrm{Mn}$ & $\mathrm{Cr}$ & $\mathrm{Mo}$ & $\mathrm{Ni}$ \\
\hline 0.08 & 0.6 & 1.7 & 0.2 & 0.5 & 1.5 \\
\hline
\end{tabular}

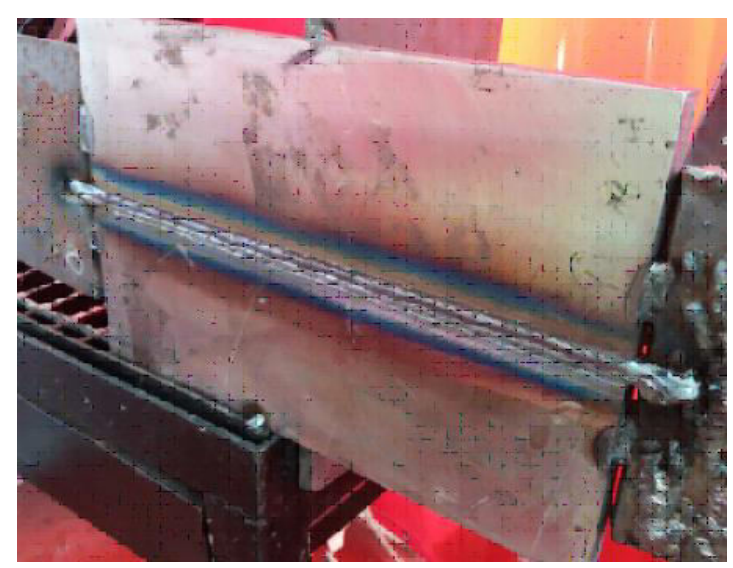

Fig.1. Welded sample of HY-80 steel after welding experiment

Welding parameters were recorded during this experiment (see Table 3). Heat input $(H)$ was calculated referring to below formula:

$$
H=E \times I \times 60 / S
$$

Where: $H=$ heat input $(\mathrm{J} / \mathrm{mm}), E=\operatorname{arc}$ voltage $($ Volt $), I$ $=$ welding current (Ampere), $S=$ arc travel speed ( $\mathrm{mm} / \mathrm{min})$.

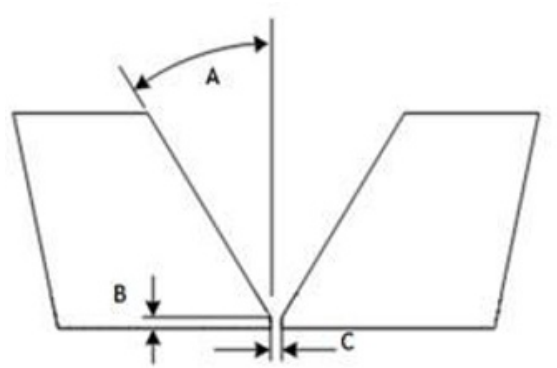

$$
\begin{aligned}
& A=\text { Groove Angle }=30^{\circ}\left( \pm 5^{\circ}\right) \\
& B=\text { Root Face }=1.0 \mathrm{~mm}-3.0 \mathrm{~mm} \\
& C=\text { Root Gap }=1.0 \mathrm{~mm}-3.0 \mathrm{~mm}
\end{aligned}
$$

Fig.2. V-groove joint design 
Table 3. Welding parameters used in the experiment

\begin{tabular}{cccccc}
\hline Sequence & Pass & $\begin{array}{c}\text { Current } \\
(\mathrm{A})\end{array}$ & $\begin{array}{c}\text { Voltage } \\
(\mathrm{V})\end{array}$ & $\begin{array}{c}\text { Welding speed } \\
(\mathrm{mm} / \mathrm{min})\end{array}$ & $\begin{array}{c}\text { Heat input } \\
(\mathrm{kJ} / \mathrm{mm})\end{array}$ \\
\hline 1 & Root & 100 & 15 & 137 & 0.66 \\
2 & Hot Pass & 170 & 18 & 286 & 0.64 \\
3 & Filler & 170 & 18 & 295 & 0.62 \\
4 & Filler & 170 & 18 & 295 & 0.62 \\
5 & Capping & 170 & 18 & 305 & 0.60 \\
6 & Capping & 170 & 18 & 273 & 0.67 \\
7 & Back weld & 170 & 18 & 353 & 0.52 \\
\hline
\end{tabular}

During welding, each pass was inspected visually. Then the completed welded sample was inspected by Xray radiography. The specimens for mechanical test and metallurgical analysis were extracted from the welded plate according to standard procedures. These specimens were cut transversally to the weld direction. Preparation of the welding procedures until weld specimens ready was carried out in according to the DNV Standard.

\subsection{Microstructural analysis}

The metallographic specimen with the dimension of $40 \mathrm{x}$ $10 \times 12 \mathrm{~mm}^{3}$ was cut to perform microstructural analysis of the weldment. The specimens were polished until mirror finish with standard metallographic procedure, it was etched with $2 \%$ nital and then hot air drying for microstructural analysis. Microstructure examinations were carried out using an optical microscope. The broken Charpy impact tested specimens also were observed.

\subsection{Mechanical tests}

The tensile test specimens were prepared according to DNV standard. These specimens were cut from the weldment with the weld metal at the middle. Tensile test was performed at room temperature $\left(25^{\circ} \mathrm{C}\right)$ by using SHIMADZU UH 100A machine with a capacity of 100 $\mathrm{T}$.

CVN test was performed by using a 300 Joule impact tester WOLPERT in various temperatures. Charpy impact test specimens of size $55 \times 10 \times 10 \mathrm{~mm}$ from welded joints were prepared according to ASTM E23 standard specification. In this study, the specimens were cut by wire cutting transversely to the weld. To ensure the position of $\mathrm{CVN}$, impact test specimens were prepared by etching with $2 \%$ nital to show the outline of WM, FL, HAZ, and BM (see Fig. 3).

$\mathrm{V}$-notch location of impact test specimen was determined at the WM, FL, and BM to examine the toughness at each location: (i) the specimens with the notches of Charpy $\mathrm{V}$ at $\mathrm{BM}$ were prepared for the test temperatures at $20,-20,-60$ and $-80{ }^{\circ} \mathrm{C}$; (ii) the specimens with the notches of Charpy $\mathrm{V}$ at WM, FL, and $\mathrm{FL}+3$ were prepared for the test temperatures at $-80{ }^{\circ} \mathrm{C}$ (see Fig. 4). Each specimen was tested twice and average values of impact toughness were taken. Impact toughness test at sub-zero temperatures were performed after immersing the specimens in the freeze box containing methanol as a cooling media. The value of energy absorbed during fracture was measured.

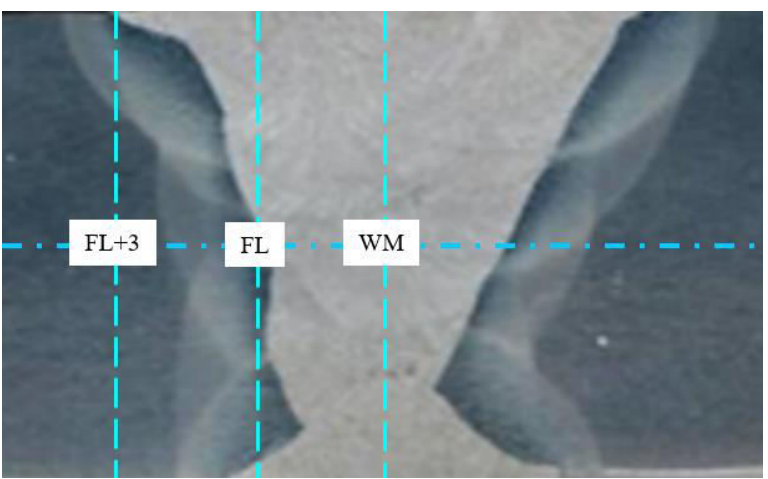

Fig.3. The outline of CVN locations
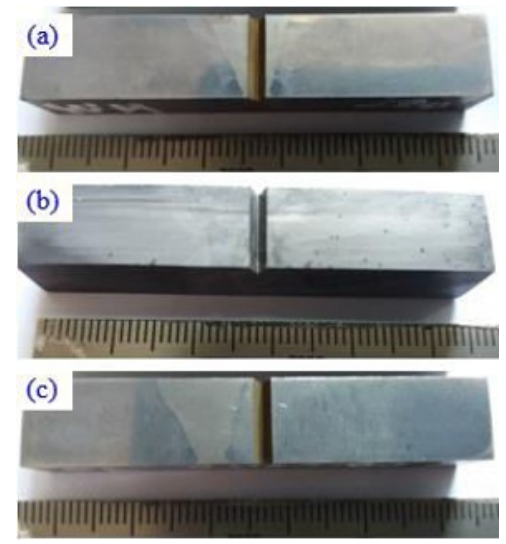

Fig.4. Test specimens of Charpy impact with V-notch location at WM (a), FL (b) and FL+3mm (c)

\section{Results and discussion}

\subsection{Microstructure analysis}

A macro photograph of HY-80 weldment has indicated that no crack or other welding defect found in the weldment. It means the GMAW method and the welding parameters used in this experiment were suitable enough for this welding experiment.

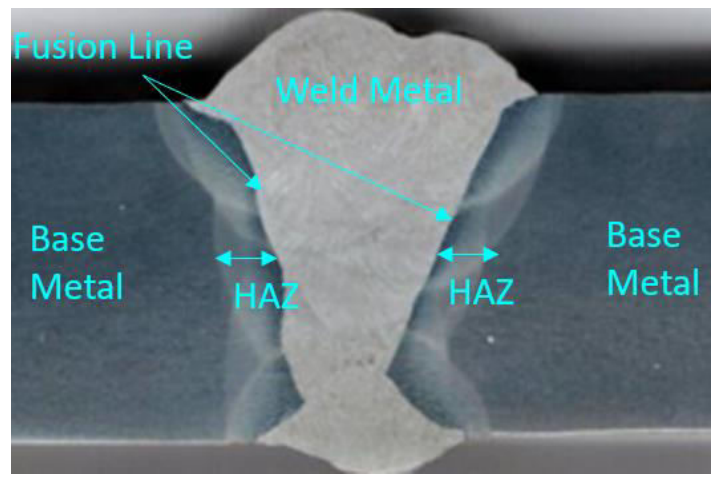

Fig.5. A macro photograph of HY-80 steel welded butt joint 
Fig. 5 shows a macro photograph of three different zones of the weldment: WM, HAZ, and BM. The HAZ indicated a zone which has microstructure evolution due to phase transformation temperature during welding, while the BM is unaffected zone.
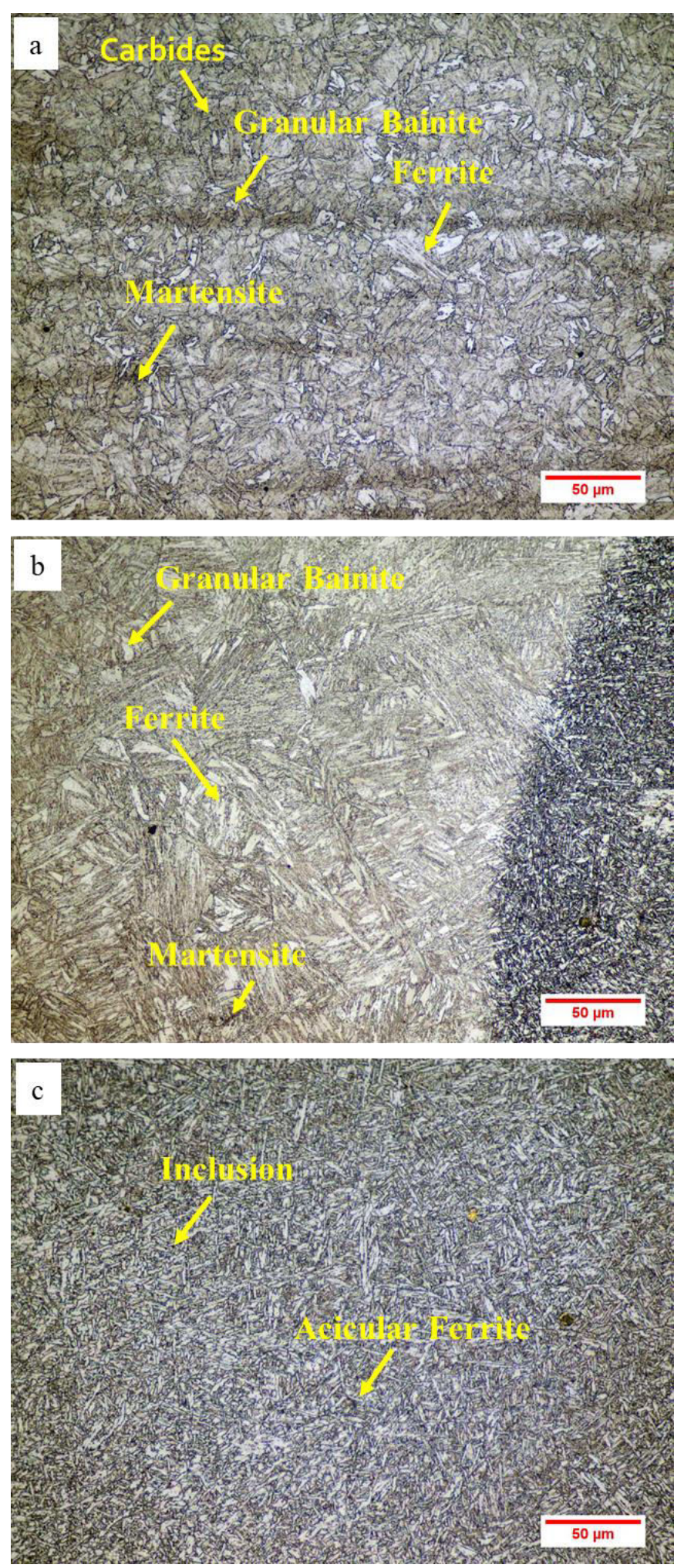

Fig.6. Microstructure of welded specimen HY-80 ( a -- BM, b - HAZ, c - WM)

Microstructure of welded specimen HY-80 was observed at $500 \times$ magnifications as shown in Fig. 6 .
Microscopic observation of BM and HAZ shows a mixture of granular bainite and tempered martensite with some carbides (Fig. 6a-b). The grains in CGHAZ indicate grain growth and relatively coarse (Fig. 6b). The microstructure of WM shows acicular ferrite and inclusions (Fig. 6c) which may influence impact toughness at sub-zero temperatures.

Acicular ferrite in WM develops during phase transformation temperatures when the austenite decomposed to different ferrite morphologies and mixture of martensite-austenite phase (M-A constituent). This is a complex process that involves the oxide inclusions, austenite stabilizer elements ( $\mathrm{Ni}$ and $\mathrm{Mn}$ ), oxygen and carbon dioxide content of the shielding gas used, welding heat input, etc. The impact toughness of $\mathrm{WM}$ at sub-zero temperatures is influenced by number of acicular ferrite which nucleate on oxide inclusion, the large size of oxide inclusion effectively for the nucleation of acicular ferrite than the small size $[7,15,17,18]$.

\subsection{Tensile test and impact toughness properties}

The tensile tests were performed for two specimens at room temperature according to DNV standard. The ultimate tensile strength (UTS) result recorded 729 $\mathrm{MPa}$ and $734 \mathrm{MPa}$. These tested specimens show the fracture occurred at BM, which indicating both HAZ and $\mathrm{WM}$ are stronger than BM. Fracture appearance shows ductile fracture where necking and cup-cone fracture shape occurred (Fig. 7)

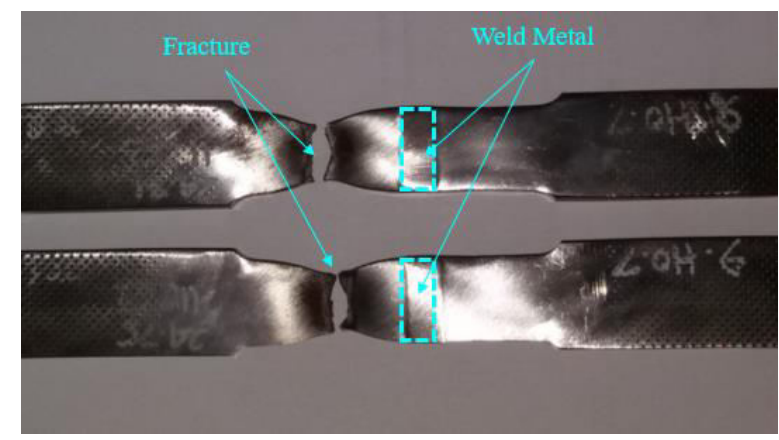

Fig.7. The fracture specimens of tensile test

The CVN tests of WM, HAZ, and BM specimens of HY-80 steel weld joint at various test temperatures have been performed. Impact energy of $\mathrm{BM}$ at various temperatures: $20,-20,-60$ and $-80{ }^{\circ} \mathrm{C}$ are shown in Fig. 8. The impact values decreased when the test temperature decreased. Fracture appearance of BM at these test temperatures show ductile fracture. Decreasing of impact energy from temperature of -60 ${ }^{\circ} \mathrm{C}$ to $-80{ }^{\circ} \mathrm{C}$ is more significant than from $20{ }^{\circ} \mathrm{C}$ to $60{ }^{\circ} \mathrm{C}$. However, at all test temperatures the impact energy values fulfilled the HY-80 standard specification according to MIL-S-16216-K(SH), this standard specifies impact energy of HY-80 steel is 47 $\mathrm{J}$ at $-84^{\circ} \mathrm{C}$ and $81 \mathrm{~J}$ at $-18{ }^{\circ} \mathrm{C}$ respectively. 


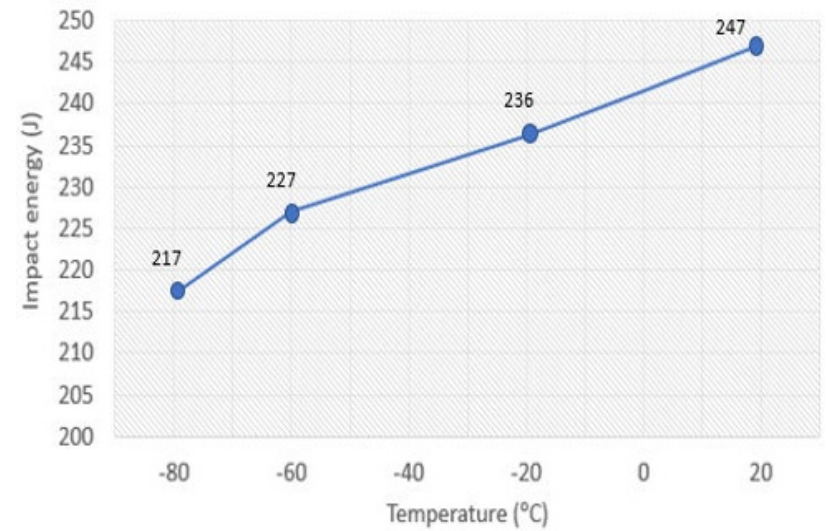

Fig.8. Impact energy vs temperature on the base metal (BM) of HY-80 steel

The impact toughness of welded joint was also tested in various locations: WM, FL, and FL+3mm. The result is presented in Fig. 9. At WM the impact energy significantly decreases and shows the lowest value. At the test temperature of $-80{ }^{\circ} \mathrm{C}$, the impact energy at $\mathrm{WM}$ is $28 \%(61 \mathrm{~J})$ and $\mathrm{FL}$ is $49 \%(101 \mathrm{~J})$ in comparing with FL $+3 \mathrm{~mm}(217 \mathrm{~J})$. The lowest impact energy at WM may occur due to oxidation affects which reduces some elements during welding [3]. Oxygen in WM may come from the use of $\mathrm{CO}_{2}$ addition to argon $\left(90 \% \mathrm{Ar}+10 \% \mathrm{CO}_{2}\right.$ shielding gas mixture). Under high temperature during welding, the $\mathrm{CO}_{2}$ decomposed into $\mathrm{CO}$ and $\mathrm{O}$ and increased the oxygen content in WM which may affect to decrease the toughness [18].

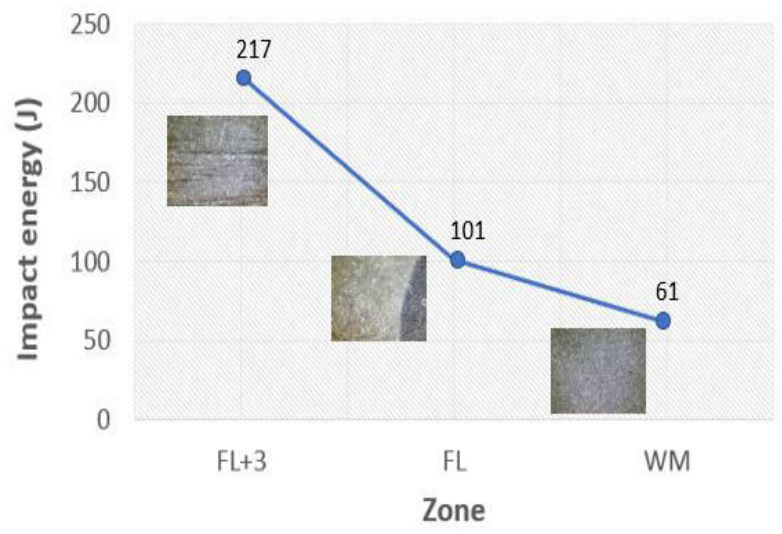

Fig.9. Impact energy (J) of HY-80 steel welds at $-80{ }^{\circ} \mathrm{C}$ in various location (WM, FL, and FL+3)

S. Kumar et al. [5] suggested the impact energy of high strength steel in HAZ is more than $50 \mathrm{~J}$ at -50 ${ }^{\circ} \mathrm{C}$. In this study, the lowest impact energy was observed at WM (61 J) and highest impact energy was at FL+3 $(217 \mathrm{~J})$. It is similar value with BM. However, the impact test result of this experiment for HY-80 in both WM and FL at test temperature of -80 ${ }^{\circ} \mathrm{C}$ show the value above $50 \mathrm{~J}$ as the investigated result of S. Kumar on the HAZ of welded high strength steel.

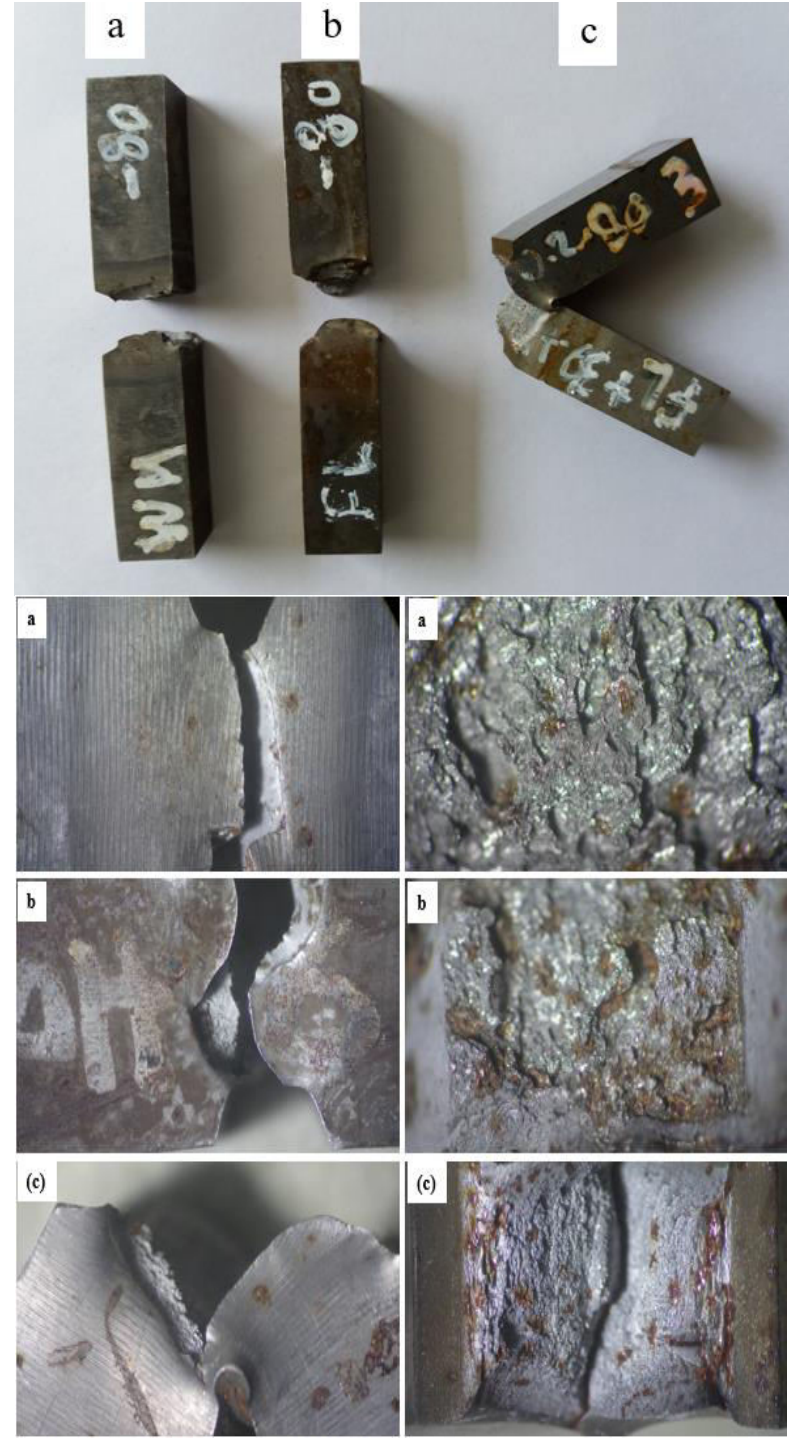

Fig.10. The fracture appearance after impact test at $-80{ }^{\circ} \mathrm{C}$ with various notch locations at: a) WM, b) FL, c) FL+3mm

These impact energy values can be compared with the results of Yayla who investigated the impact energy of HY-80 steel welded at $-20{ }^{\circ} \mathrm{C}$ which show the lowest value at WM (65 J) and higher value at HAZ $(125 \mathrm{~J})$ while $\mathrm{BM}$ show the highest $(260 \mathrm{~J})$ [3]. V. Grabulov [11] who investigated the weldability of NN 70 steel (class of HY-100) suggested the toughness of $\mathrm{WM}$ is lower than HAZ in the range temperatures from $-140{ }^{\circ} \mathrm{C}$ to $20^{\circ} \mathrm{C}$.

The broken specimens (Fig. 10) show that the fracture appearance are brittle fracture after impact test at $-80^{\circ} \mathrm{C}$ on WM and HAZ specimens where the specimens broken on a flat plane. Ductile fracture was observed at FL $+3 \mathrm{~mm}$ specimens that are still indicated a plastic deformation.

\section{Conclusions}

In the study on impact toughness of HY-80 steel welded joint at sub-zero temperatures, the conclusions are as follows: 
1. GMAW operation is suitable enough for multi pass welding process of the HY-80 steel plates based on the test results of tensile strength and impact toughness of weld joint.

2. Impact energy of BM at various temperatures (20, $20,-60$ and $-80{ }^{\circ} \mathrm{C}$ ) decreases when the temperature decreases, however the impact energy at all test temperatures fulfilled the minimum value as specified for HY-80 steel plate standard according to MIL-S-16216-K(SH).

3. At the lowest temperature of $-80{ }^{\circ} \mathrm{C}$, the impact energy at WM show the lowest value (28\% of BM) followed by FL ( $49 \%$ of BM), however this value is still above the minimum value for the standard of HY-80 steel plate.

4. Fracture mode of the BM shows ductile fracture at various test temperatures $\left(20,-20,-60\right.$ and $\left.-80{ }^{\circ} \mathrm{C}\right)$.

5. The impact test results for HY-80 steel welded plates at temperature of $-80{ }^{\circ} \mathrm{C}$ show fracture appearance of WM and FL are brittle fracture, while $\mathrm{BM}$ is ductile fracture.

The authors wish to thank the financial support from Direktorat Riset dan Pengabdian Masyarakat Universitas Indonesia (DRPM-UI) for sponsoring the research through the PITTA Research Grant in 2017.

\section{References}

1. D. Ellis, Monterey, Naval Postgraduate School, California (1990)

2. K. Sampath, Welding Journal pp.131-138 (2005)

3. P. Yayla, E. Kaluc, K. Ural, Materials and Design 28: 1898-1906 (2007)

4. G.A. Patella, Rensselaer Polytechnic Institute, Hartford, CT (2014)

5. S. Kumar, S.K. Nath, Journal of Materials Processing Technology 236: 216-224 (2016)

6. K. Prasad, D.K. Dwivedi, Int J Adv. Manuf Technol 36: 475-483 (2008)

7. R. Pamnani, T. Jayakumar, M. Vasudevan, T. Sakthivel, Journal of Manufacturing Processes 21: 75-86 (2016)

8. S. Ragu Nathan, V. Balasubramanian, S. Malarvizhi, A.G. Rao, Defense Technology 11: 308-317 (2015)

9. Markku Pirninen, Lappeenranta University of Technology, Lappeenranta, Finland (2013)

10. R. Cao, J. Li, D.S Liu, J.Y. Ma, J.H. Chen, Metallurgical and Materials Transactions A, Vol. 46A: 2999-3014 (2015)

11. V. Grabulov, International Conference - Innovative technologies for joining advanced materials tima09 (2009)

12. H. Dong, X. Hao, D. Deng, Metallogr. Microstruct. Anal. 3: 138-146 (2014)

13. S. Kumar, S.K. Nath, V. Kumar, Materials and Design 90: 177-184 (2016)

14. Winarto, M. Anis, Taufiqullah, Material Science Forum, Vol. 689: 269-275 (2011)
15. J.E. Ramirez, Welding Journal Vol. 87: 65-75 (2008)

16. S. Mukhopadhyay, T.K Pal, Int J Adv. Manuf Technol 29: 262-268 (2006)

17. Liangyun, Xiangwei, Chunlin, Dewen, Materials and Design 90: 488-498 (2016)

18. S. Kou, Welding Metallurgy $2^{\text {nd }}$ ed. : 73, WileyInterscience publication, New Jersey (2003) 